\title{
The study on the efficiency of a photovoltaic cell with a system of supercapacitors and batteries
}

\author{
Dariusz Strąk ${ }^{1, *}$, Kinga Strąk $^{1}$, and Magdalena Piasecka $^{1}$ \\ ${ }^{1}$ Kielce University of Technology, Faculty of Mechatronics and Mechanical Engineering, al. 1000-lecia P.P. 7, 25-314 Kielce, Poland
}

\begin{abstract}
The main aim of this work is to propose a new system of a hybrid photovoltaic system working with batteries and supercapacitors and to analyze its efficiency. The preliminary results of the study on the operation of the system are discussed. The results obtained while testing the operation of a hybrid system and a PV system working separately with batteries and supercapacitors are compiled and compared. The tests covered the systems efficiency for the following electrical loads: heater warming up water in a tank, and lighting - a LED light. The work of batteries and supercapacitors during discharge has been analysed. The use of a hybrid system made it possible to increase energy storage efficiency and the system operation flexibility, compared to solar systems offered by the sector.
\end{abstract}

\section{Introduction}

One of the key trends of today's world economy is the shift from the marginal to mainstream use of renewable energy as an alternative to fossil-fuel based energy production. The last several years have seen extensive research related to the renewable energy technology, with solar photovoltaic (PV) regarded as one of the most promising. The main role of PV system deployment is to support residential electrical, central heating and hot water systems as a supplementary energy source, or to serve as a standalone power source at sites where gridconnection is impossible or impractical, such as street lighting or luminous road signs. An example of PV deployment is energy generation from micro-grids using three monocrystalline solar panels with a rated power $585 \mathrm{~W}$ in a residential building [1], where the PV system pays for itself. Another example is the PV system (26.6 KWp) installed to provide electricity for a bus repair shop [2]. The system has twofold benefits; one is cost-related - reduced amount of energy purchased from the current supplier and the other one is ecological reduced emission of carbon dioxide into the atmosphere.

A need for energy storage is created by increased demand for charging batteries (Bs) and supercapacitors (SCs) through photovoltaic systems. Solar energy acquisition in regions with inadequate solar irradiation is problematic. In conventional systems, PV energy is stored only by batteries that, at low power density, have high energy density and use high currents or high frequency currents for charging. The life of the battery (Bat) in PV systems is quite short. In comparison with Bs, SCs allow a hundred times higher power density, with ten times lower energy density. Undergoing frequent charge/discharge cycles at high current and frequency does not shorten SCs life. The use of hybrid energy storage enhances the reliability of the system at various variable current conditions and increases the efficiency of the system under variable solar irradiation [3].

Researchers in [4] present an embedded energy share method between batteries (the energy storage system) and supercapacitors (the auxiliary energy storage system) in which supercapacitors improve the life of the batteries and reduce their stress by providing/absorbing peaks currents as demanded by the load. Simulation results illustrate the performance of the proposed control strategy.

The use of supercapacitors (SCs) to improve battery life and reduce the life cycle cost of a standalone photovoltaic $\mathrm{PV} /$ Bat system for a remote agricultural farm power application is discussed in [5]. The authors analyze the performance of a PV/Bat and a PV/Bat/SC systems in a typical remote agricultural feedmill.

Another scheme to control the power sharing between batteries and supercapacitors is reported in [6]. The researchers introduce an innovative method for sizing the energy storage system together with the hybrid distribution based on the photovoltaic power curves to reduces the stress levels on the battery, extend its life, and provide constant power injection to the grid over a defined time interval.

In [7] a system able to integrating a photovoltaic generation system, including the energy storage to moderate fluctuations in the energy generated, by using a set of supercapacitors are presented. The system consists of a voltage source inverter and a bidirectional direct current converter regulating the charge of the supercapacitor.

A simple novel control strategy for a hybrid energy storage system is elaborated and analyzed in [8]. In the method proposed by the authors, batteries are used to

Corresponding author: $\underline{\text { dstrak@tu.kielce.pl }}$ 
counterbalance the slow changing power surges. A supercapacitors (SCs) are applied to equiponderate the fast changing power surges. The slow response of battery system is overcome by diverting the power surges to the SCs system and reduce the current stresses on battery.

In [9] an nonlinear flatness control applied to supercapacitors contribution in hybrid power systems by using photovoltaic source and batteries is shown. Two systems are desribed to manage energy flows: the first with a photovoltaic (PV) source considered and leadacid batteries used as storage unit and the second hybrid system with the PV source, lead-acid batteries, and supercapacitors. In the system control, the nonlinear flatness control is used to manage energy. Under conditions of high discharges, supercapacitors allow batteries to operate under reasonable conditions limiting strong solicitations and keeping them in a higher state of charge. The use of supercapacitors in a hybrid system increases sources lifetimes battery.

A simple scheme of the supercapacitor based on (RC) circuit by using experimental methods is modeled and characterized in [10]. It is an example of hybrid photovoltaic/supercapacitor stand-alone system. There is applied the maximum power point tracking (MPPT) control for photovoltaic and the supercapacitor state of charge (SOC) control. A simulation model is developed for the considered hybrid energy system by using MATLAB/Simulink. The results present the main role of the supercapacitor when the load changes rapidly.

In [11] the role of the supercapacitor in a PV energy control unit (ECU) by using Matlab/Simulink models is discussed. According to authors, the hybrid storage system can achieve higher specific power than the battery storage system. An alternative way of supplying large bursts of current is to combine VRLA batteries and supercapacitors to form a hybrid storage system where the battery can supply continuous energy and the supercapacitor can supply the instant power to the load.

The storage of photovoltaic energy by supercapacitors is studied in [12]. The experimental setup consists of a photovoltaic array, a module of supercapacitors in series, electrical relays, and a resistive load. Analog to digital converters are used, and an interface has been developed with Labview software. The second approach consists in simulating photovoltaic energy storage by supercapacitors with a model composed of solar irradiance evaluation, equivalent electrical circuit for photovoltaic conversion, and a multibranch circuit for supercapacitor. Both the experimental and calculated results are confronted, and an error of $1 \%$ on the stored energy is found with a correction largely within $\%$ of the transmission line capacitance according to temperature.

In [13] is proposed a hybrid generator with a photovoltaic energy conversion system supercapacitors and lead-acid batteries. The task of this system is to provide active power to the electricity grid. By designing a control system it is possible to ensure a high battery state of charge and overcharge security. A continuous dynamic model is used and a control design of the power system is studied.
Use of supercapacitors as energy storage systems is evaluated in [14]. Supercapacitors are compared with other technologies such as: compressed air, pumped hydro, superconductors and flywheels. The supercapacitors are studied in detail, presenting device structures, how they can be modeled, the balancing, their useful life and principal applications.

In [15] intelligent systems data collection and processing in the different applications where supercapacitors are used, such as: automatic highway traffic management, area surveillance, and geological activity monitoring are discussed. Key and basic field systems that are away from the power grid infrastructure energy are self-sustainability. Instead of the conventional battery-based energy storage, the buffer solar energy in supercapacitors has the advantages of precise energy lifetime awareness, low maintenance, and operational robustness. The load can also consume energy directly from PV Solar Energy Harvesting Circuit built around connected via SEPIC DC-DC converter.

A system that supercapacitors are an emerging choice for energy buffering in field systems is studied in [16]. Supercapacitors offer advantages compared to rechargeable batteries for energy buffering due to their energy charge and discharge efficiency as well as environmental friendliness.

A special class of converters as the energy transfer mechanism DC-DC are described in [17]. The most commonly used DC-DC converter designs are Buck and Boost or Buck-Boost.

According to [18], SEPIC is a reasonably efficient solution for a an energy transfer circuit that is providing current into a supercapacitor. It can be used with systems built with supercapacitors.

In [19] presents of the high frequency DC/DC converter built on the basis of silicon carbide elements (SiC). The converter has the ability to bi-directionally lower and increase the voltage, which allows the energy flow in both directions regardless of the input voltage to the output voltage. $\mathrm{SiC}$ elements used are characterized by higher efficiency about devices from silicon elements.

The concepts of the battery-supercapacitor PV system applied in a system of energy generation and storage in public and long-distance transport vehicles and for unmanned aerial vehicle are proposed in [20, 21], respectively.

The main aim of this work is to propose a new system study of a photovoltaic cell with a system of supercapacitors and batteries and to analyses its efficiency. The preliminary results of the study on the operation of a hybrid photovoltaic system working with batteries and supercapacitors were discussed.

\section{Experimental stand and methodology}

Figure 1 shows a diagram of a storage system for energy from photovoltaic panels, which use batteries and supercapacitors to store energy. 


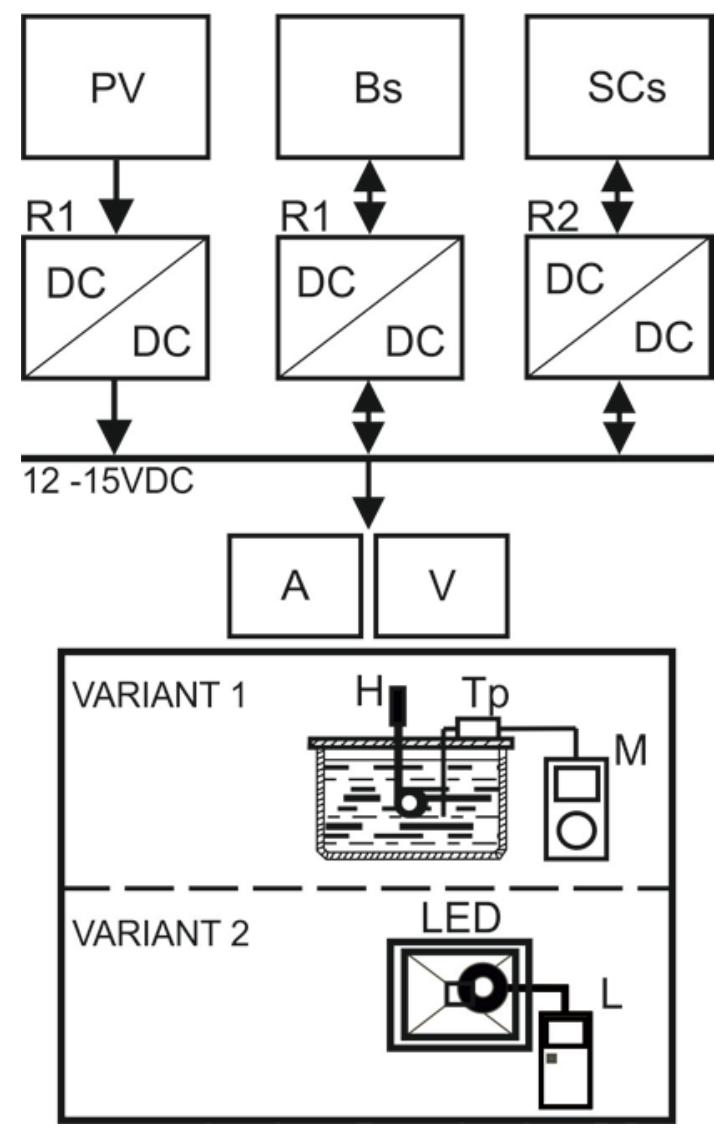

Fig. 1. Photovoltaic system working with a $12 \mathrm{~V}$ load, using SCs and Bs: PV- photovoltaic panel, Bs - batteries, SCs-supercapacitors, R1-PWM charge controller, R2-pulse type charge controller, A-ammeter, V-voltmeter, L-luxmeter, H-heater, LED-a LED light, M-multimeter, T-thermocouple.

Direct current generated in PV cells is delivered to solar voltage controller PWM (R1), and to the energy storage unit. The SCs are provided with a progressive pulse type voltage charge controller (R2) connected to the Bs, which is to charge the SCs and to protect against overcharging and polarity reversal in a system of connected SCs. As soon as the SCs are charged, the energy is transferred using Schottky diode with nominal operating parameters: $300 \mathrm{~A}$ and $30 \mathrm{~V}$, which secures the system against SCs polarity reversal to the output to electrical loads. At the output from the diode system current is measured using an ammeter $400 \mathrm{~A}$ (A) and voltmeter (V). Rated parameters of the PV panels, SCs, Bs and voltage charge controllers are specified in Table 1. Current collection system is provided with heater $(\mathrm{H})$ with rated operating parameters: voltage - $12 \mathrm{~V}$ and power - $200 \mathrm{~W}$, or a LED light - power $50 \mathrm{~W}$ and voltage $12 \mathrm{~V}$. A luxmeter, Voltcraft, type PL-110SM (L) was used to measure light intensity of the lighting system and the PV. Ambient temperature and temperature of water in the tank was measured with $\mathrm{K}$-type thermocouples.

The experimental stand allows parallel charging of both SCs and Bs. In case if Bs are fully charged, the energy is transferred to the SCs charging system. The system contains conductors made of soft copper. The SCs system is connected in series, the aggregate value of resistance for the entire system is ca. $4.2 \mathrm{~m} \Omega$ (not including resistance of load connected to the system), and power is $5 \mathrm{~kW}$. Voltage at the output of fully charged SCs system is $15 \mathrm{~V}$, and current intensity is $700 \mathrm{~A}$.

Table 1. Rated parameters of a solar system, the complex of Bs and SCs.

\begin{tabular}{|c|c|c|c|}
\hline \multicolumn{4}{|c|}{ Charge controllers } \\
\hline \multicolumn{2}{|c|}{ Parameters } & $\begin{array}{c}\text { Charge } \\
\text { controller } \\
\text { R1 } \\
\end{array}$ & $\begin{array}{l}\text { Pulse type } \\
\text { charge } \\
\text { controller R2 }\end{array}$ \\
\hline \multicolumn{2}{|l|}{ Rated voltage, $\mathrm{V}$} & $12 / 24$ & $12-15$ \\
\hline \multicolumn{2}{|l|}{ Min. input voltage, $\mathrm{V}$} & 10.5 & 6 \\
\hline \multicolumn{2}{|l|}{ Max. charge current, $\mathrm{A}$} & 60 & 30 \\
\hline \multicolumn{2}{|l|}{ Max. load current, $\mathrm{A}$} & 60 & 30 \\
\hline \multicolumn{2}{|l|}{ Charging technology } & PWM & Pulse \\
\hline \multicolumn{2}{|l|}{ Charging time } & $1 \mathrm{~h}$ to $24 \mathrm{~h}$ & from $100 \mathrm{~s}$ \\
\hline \multicolumn{2}{|c|}{ Charging to output current, $\mathrm{A}$} & - & 400 \\
\hline \multicolumn{4}{|c|}{ Rated parameters of a system containing $4 \mathrm{PV}$ panels } \\
\hline \multicolumn{3}{|c|}{\begin{tabular}{|c|c|} 
Parameters & \\
\end{tabular}} & \multirow{2}{*}{$\frac{\text { PV }}{\text { SGM-170 W }}$} \\
\hline \multicolumn{3}{|l|}{ Model } & \\
\hline \multicolumn{3}{|l|}{ Type } & monocrystals \\
\hline \multicolumn{3}{|c|}{ Power tolerance, $\%$} & \pm 3 \\
\hline \multicolumn{3}{|c|}{ System voltage, $\mathrm{V}$} & 12 \\
\hline \multicolumn{3}{|c|}{ Rated voltage, $\mathrm{V}$} & 17.8 \\
\hline \multicolumn{3}{|c|}{ Charging current, $\mathrm{A}$} & $4 \times 9$ \\
\hline \multicolumn{3}{|c|}{ Power of the PV system, W } & $4 \times 169.9$ \\
\hline \multicolumn{3}{|c|}{ Cell efficiency, $\%$} & 18.43 \\
\hline Operating paramet & s o & the Bs and & Cs system \\
\hline Parameters & & Bs & SCs \\
\hline Qty. pcs. & & 2 & 6 \\
\hline Model & & WL $120-12 \mathrm{~h}$ & BCAP - 3000 \\
\hline Capacity & & $240 \mathrm{Ah}$ & $90000 \mathrm{~F}$ \\
\hline Voltage, V & & 12 & 15 \\
\hline E, Wh & & 2000 & 18.225 \\
\hline Energy density, Wh/kg & & 84.80 & 60.75 \\
\hline
\end{tabular}

For the purposes of analysing the results of the system operation and evaluating its efficiency, loading of the system consisting of the Bs, SCs and PV panels is used at the experimental stand, applied in two variants: analysis of water heating time in an insulated tank (capacity $1 \mathrm{dm}^{3}$ ) with a $200 \mathrm{~W}$ heater up to the temperature of $45{ }^{\circ} \mathrm{C}$ (variant I), and measurement of obtained power and lighting intensity of a $50 \mathrm{~W}$ LED light (variant II).

The tests were performed in laboratory conditions in Kielce on May 15, 2018, at atmospheric pressure of $992.62 \mathrm{hPa}$ and ambient temperature $27.7^{\circ} \mathrm{C}$.

\section{Results}

\subsection{Energy balance for the employed hybrid system}

Energy generated by a complex of photovoltaic panels, stored in Bs, SCs and used by electrical loads, has been defined as:

$$
\begin{gathered}
E_{O B}=E_{P V}-E_{B}-E_{S C} \\
E_{P V}=\int_{0}^{24} f(x) d x
\end{gathered}
$$




$$
\begin{gathered}
E_{S C}=\int_{x_{1}}^{x_{2}}\left(f(x)-g(x)+\frac{C}{10}\right) \\
E_{B}=\int_{x_{3}}^{x_{4}}\left(f(x)-g(x)-E_{S C}\right)
\end{gathered}
$$

where: $E_{O B}$ - energy delivered to the loads, $E_{P V}$ - energy generated by the complex of photovoltaic panels, $E_{S C}$ - energy stored in SCs, $E_{B}$ - energy stored in Bs, $C$ - capacity of Bs.

Figure 2 presents electrical output power plot for a complex of $680 \mathrm{~W}$ photovoltaic panels, similar as in [4].

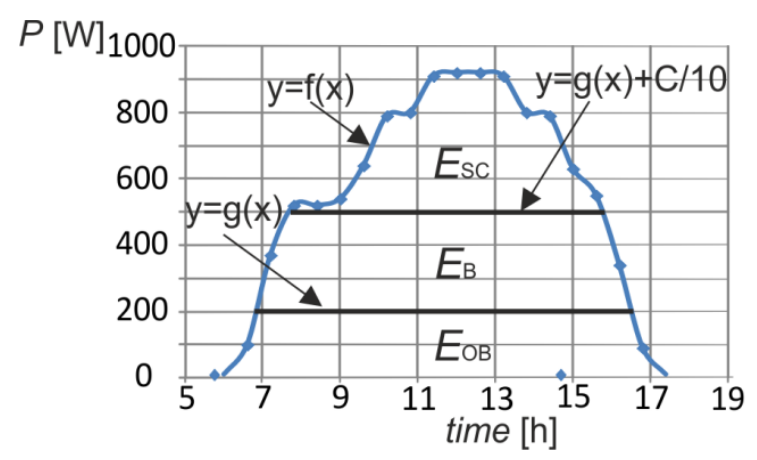

Fig. 2. Output power characteristics for a complex of photovoltaic panels; Esc - energy stored in SCs, $E_{B}$ - energy stored in $\mathrm{Bs}, E_{O B}$ - energy consumed by the load.

\subsection{Testing of the supercapacitors and batteries charging characteristics}

Figure 3 shows voltage in function of time, and Fig. 4 shows current intensity in function of time, during the SCs and Bs charging.

The SCs system is characterised by very fast charging process, from 5 to 8 minutes, low internal resistance (even below $0.9 \mathrm{~m} \Omega$ ), minor internal energy losses, high efficiency (exceeding 95\%), and short recharging times. For the Bs system charging time is few hours only. Analysis of the results shown in Fig. 3 shows that the time of SCs charging to $15 \mathrm{~V}$ is 7 minutes, (Fig. 3a), while for the Bs complex it takes ca. 4.5 hours to reach $13.4 \mathrm{~V}$ (Fig. 3b). There is a big difference between the Bs and SCs charging time. While analysing diagrams of the SCs charging with the intensity of current taken from the Bs in relation to time, Fig. $4 \mathrm{a}$, it is visible that at the initial stage of charging, current intensity was $0.5 \mathrm{~A}$, and then it increased to $16 \mathrm{~A}$. After few seconds of this work, the third stage began, during which the R2 controller started to increase current intensity gradually to $27 \mathrm{~A}$. Then, current intensity remained at constant level in time.

Figure $4 \mathrm{~b}$ shows that for $\mathrm{Bs}$ charging, current intensity remained at constant level $(10 \mathrm{~A})$ between 0 and 3 hours. Then, current intensity dropped with increasing battery charge time to $3.8 \mathrm{~A}$. a)

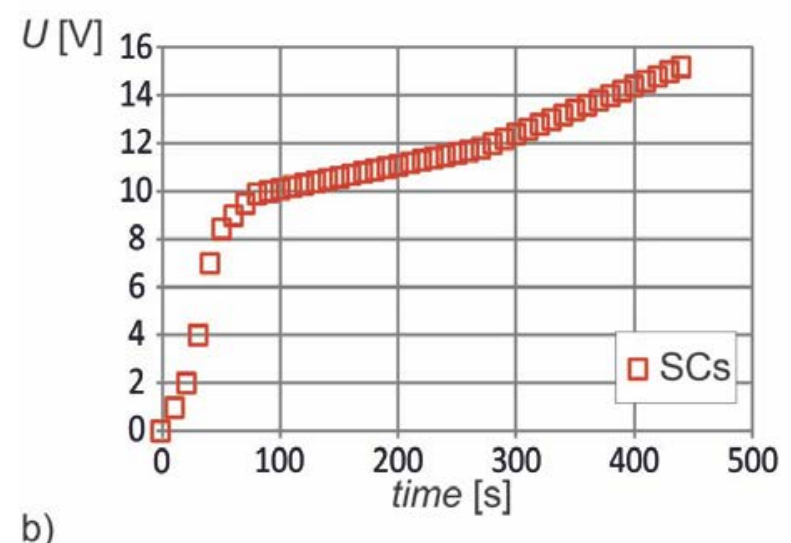

$U[\mathrm{~V}]$

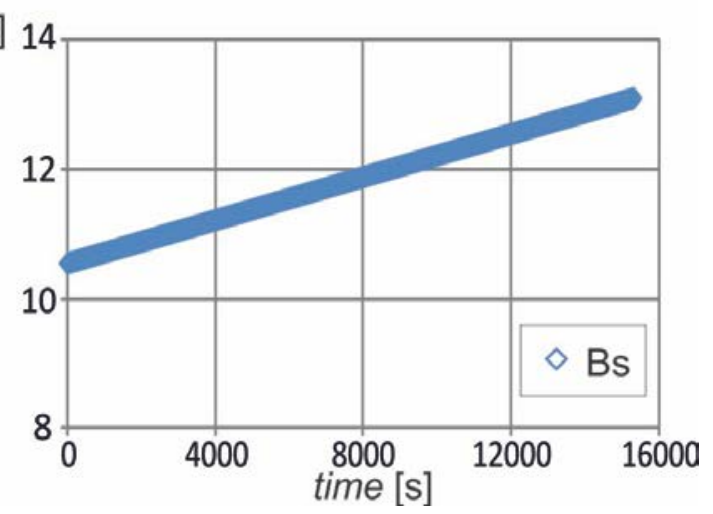

Fig. 3. The voltage versus time, while charging SCs (a) and Bs (b).

a)

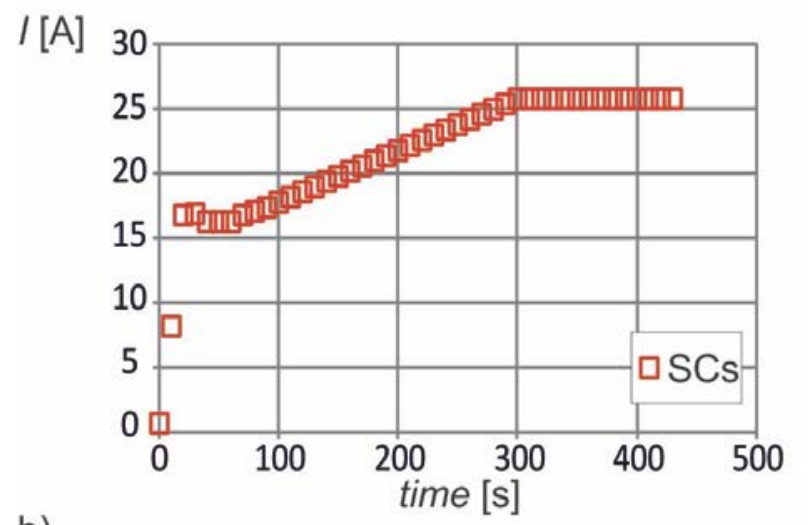

b)

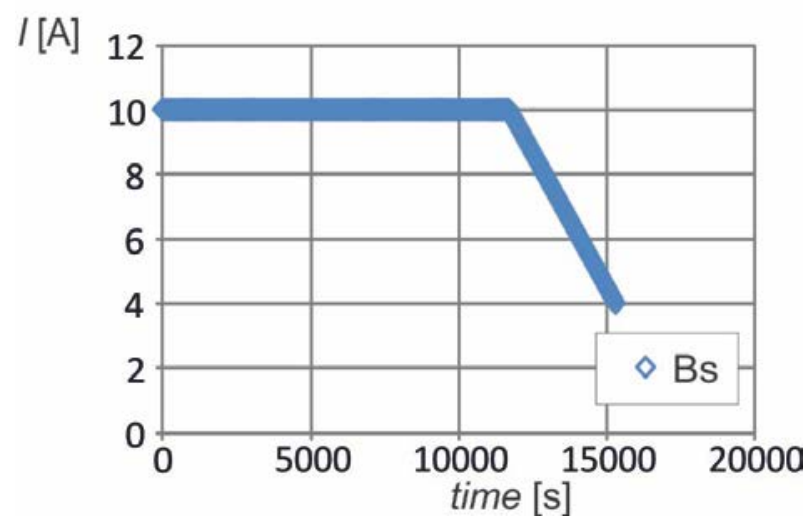

Fig. 4. The current intensity versus time, while charging SCs (a) and Bs (b). 


\subsection{Results of tests with electrical load, variant 1}

Figure 5 presents operation characteristics for the system with heater (variant I), in form of the following relationships: heater power consumption in function of time (Fig. 5a), and water heating rate in time (Fig. 5b) for the PV system working only with the SCs, or only with the Bs. The batteries were being discharged for 25 minutes (Fig. 5a), without recharging by the PV panels at high current intensity reaching $10 \mathrm{~A}$ (heater connected). In this time, heater power consumption indicated drop in battery charge power from $84 \%$ to $60 \%$. The temperature of water in the tank increased from $23.4{ }^{\circ} \mathrm{C}$ to $45^{\circ} \mathrm{C}$ within approximately 17 minutes (Fig. 5b). The results are much the same both for Bs and SCs.

a)

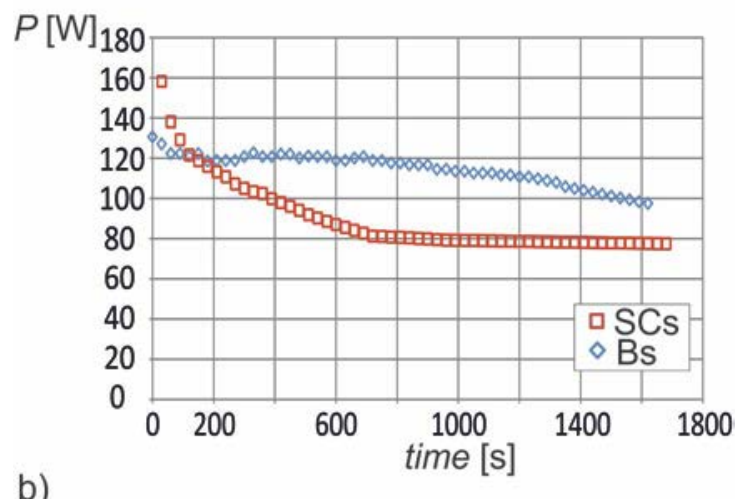

b)

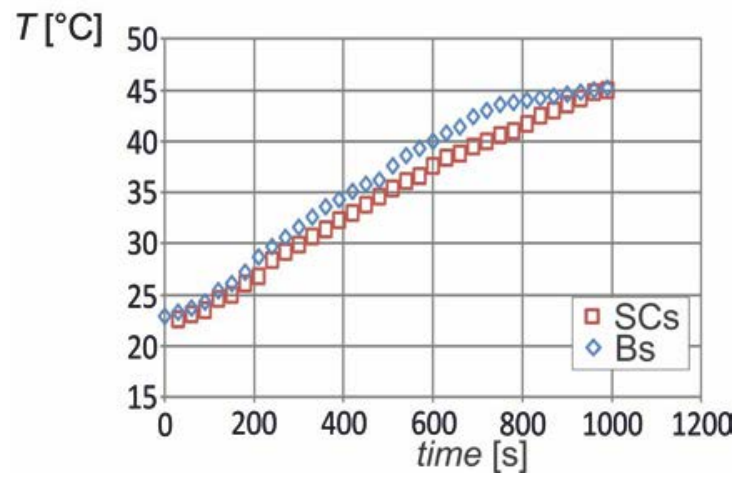

Fig. 5. a) Heater power consumption in function of time, b) the rate of water heating in time in a $1 \mathrm{dm}^{3}$ tank; data shown for SCs and Bs, separately.

Figure 6 shows drop of voltage and current intensity for the heater in function of time for the hybrid system, where the SCs were recharged from the Bs. SCs voltage remained close to $10.5 \mathrm{~V}$ after 23 minutes, while for Bs after 30 minutes, Fig. 6a. Initial current intensity for the SCs and Bs was approximately 10.5 A, Fig. 6b. For the Bs, current intensity remained stable $(9.8$ A) after 3 minutes. For the SCs, gradual drop in current intensity to $7.8 \mathrm{~A}$ was observed within 14 minutes. Later, amperage remained stable. a)

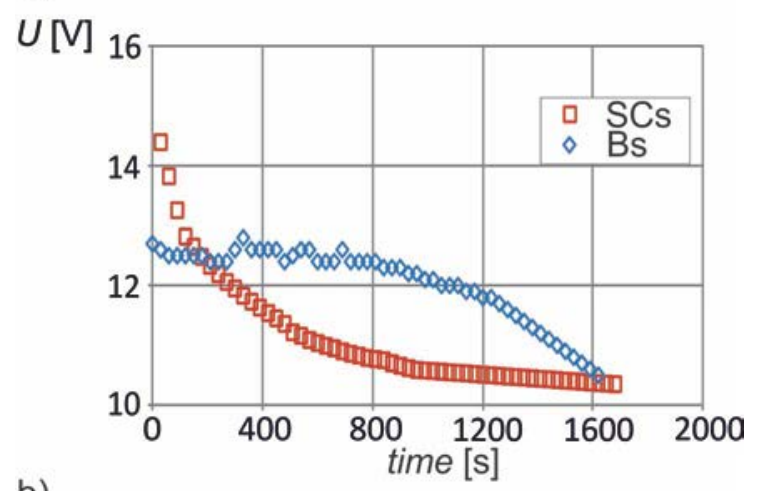

b)

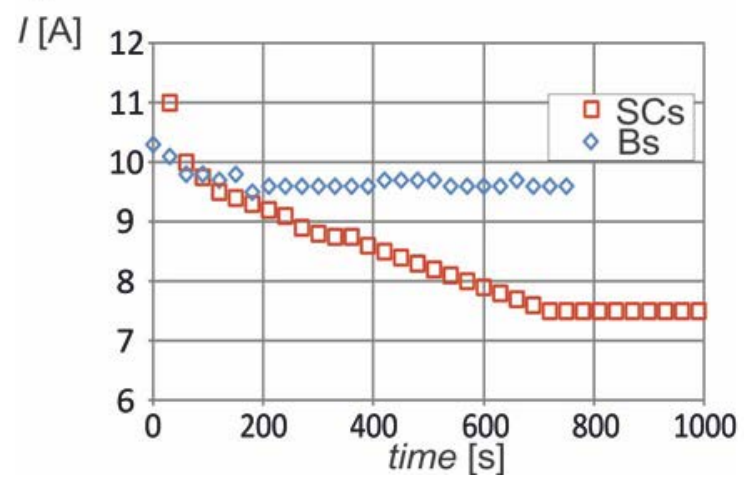

Fig. 6. Relationship of heater loading in relation to time for: a) voltage, b) current intensity; achieved for the hybrid system (PV with SCs and Bs).

\subsection{Results of tests with electrical load, variant II}

Figure 7 presents the relationships for the hybrid system in function of time, while the SCs were charged by R2 with the LED light connected as a load for:

- Bs voltage during charging and discharging, Fig. 7a,

- percent discharge of Bs during the SCs charging, Fig. $7 b$.

Time of the SCs recharging at regular intervals was ca. 6 minutes. Initial Bs charge was $78 \%$, and the SCs charge controller activated charging process every 5 minutes, then power in the Bs was cyclically dropping to $70 \%$, Fig. $7 \mathrm{a}$. In the hybrid system with the SCs, voltage was slightly dropping during the SCs charging. The LED light intensity was approximately 150 lux and remained stable in time.

Figure 8a shows current intensity in function of time for the Bs and the SCs during discharge, for a hybrid system. Initial power consumption for the Bs was 13.4 A, and for the SCs - 2.5 A. In 28 minutes amperage dropped from $4 \mathrm{~A}$ to $0.5 \mathrm{~A}$. For the SCs load the LED light stopped working after 50 minutes (Fig. 8b). Whereas, for the Bs load the lamp went off at $10.5 \mathrm{~V}$. Therefore, even at as low voltage as $4 \mathrm{~V}$ the SCs reach current intensity allowing operation of the LED light. 
a)

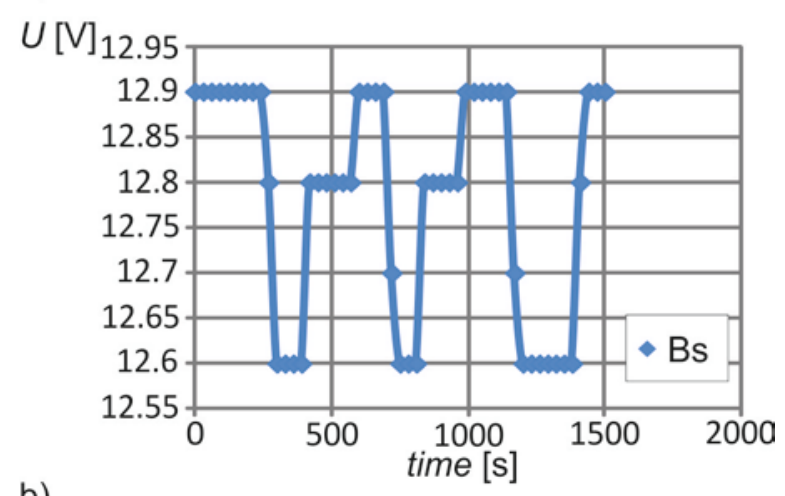

b)

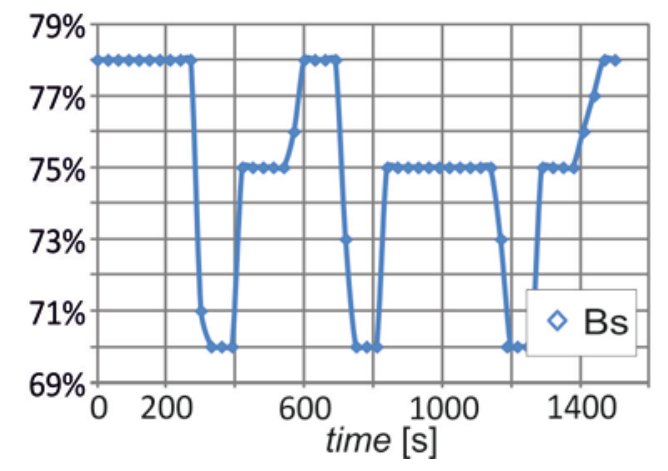

Fig. 7. Relationships for the hybrid system in function of time, while the SCs were charged by the R2 with the LED light connected as the load: a) voltages for the Bs during charge and discharge, b) percent discharge of the Bs while charging the SCs.

a)

b)
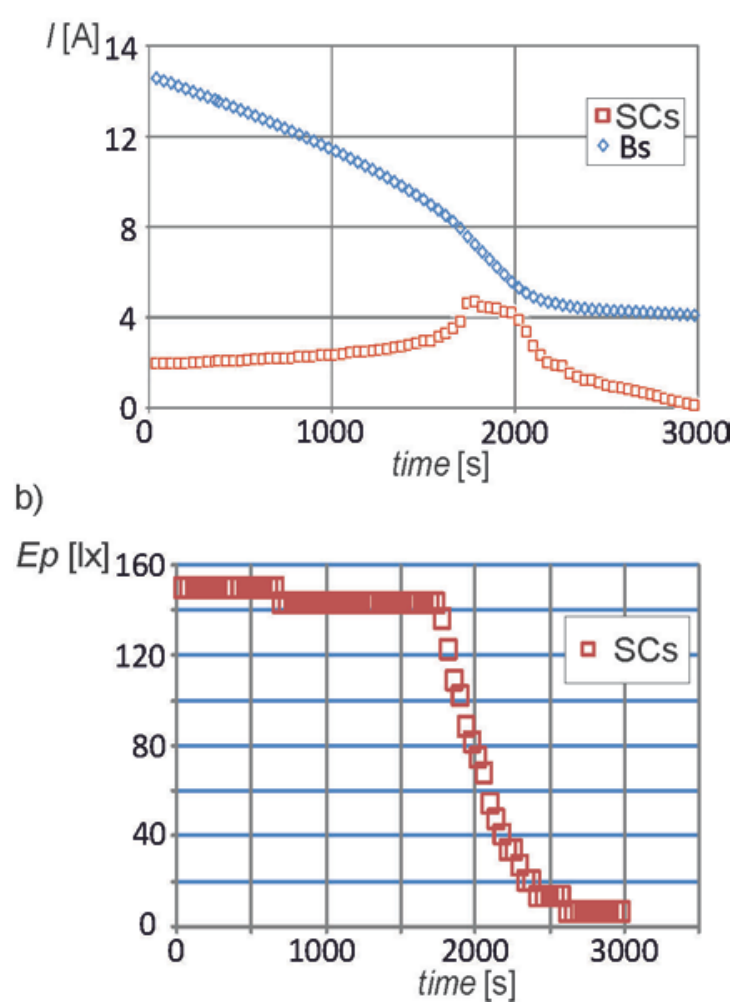

Fig. 8. Relationships for the hybrid system in function of time: a) current intensity drawn by the LED light, b) intensity of light emitted by the LED light during the SCs loading.

\subsection{Comparison between operation of batteries and supercapacitors}

The results of tests and measurement characteristics of the system allow stating that the SCs system is the most prospective energy storage system. Its advantage is high power density, with short charging times (recharging) of only few minutes, compared to the Bs. Batteries are sensitive to excessive discharge, which reduces their capacity and service life. The SCs have lower selfdischarge current values compared to the Bs.

The hybrid system proved to have better operating effects than the Bs system with PV. For variant I, with heater as an electrical load, the hybrid system was faster to warm up water to $45^{\circ} \mathrm{C}$, while for variant II with the LED light it considerably improved smooth exchange of accumulated energy and stabilised light intensity at 150 lux. The demonstrated hybrid energy accumulation system allows reducing operation time of batteries used during the tests, while original system efficiency is maintained. Improved parameters of the system buffer have been reached after introducing the SCs connected to the Bs. In this setup the SCs are the final energy storage units. In power consumption system the $\mathrm{SCs}$ receive energy from the Bs. In this system, when there is surplus solar energy available, the Bs and SCs are charged in parallel while the system is loaded, and the energy is delivered by photovoltaic panels. When hybrid system in not loaded, the energy is fully accumulated in batteries and supercapacitors. Using the SCs in this system made it possible to obtain energy accumulation reached $95 \%$. In a similar situation, accumulation energy was estimated to be $78 \%$ for the Bs. In the examined hybrid system the loads receive energy from the SCs first, and they consume only insignificant portion of energy from the Bs.

\section{Conclusions}

The paper presents results of a preliminary study on a photovoltaic system working with the system consisting of SCs and Bs (a hybrid system). Moreover, the research involved comparison of the work of Bs and SCs during discharge for two electrical loads: a heater warming up water, and lighting - a LED light. The Bs charge power (while charging the SCs) was dropping from approx. $80 \%$ to $70 \%$, which would considerably improve smooth exchange of accumulated energy, compared to direct connection between the load and the Bs. Batteries are sensitive to excessive discharge, their capacities decrease in time, and their service life is shorter. The system consisting of SCs is characterised by very fast charging process, high efficiency, short recharging times, and lower self-discharge current values. When heater was an energy consuming load, the $\mathrm{SCs}$ heated up water to preset temperature faster than the Bs.

Generally, the use of a hybrid system made it possible to increase energy storage efficiency and the system operation flexibility, compared to solar systems offered by the sector. 


\section{References}

1. J. Dąbrowski, E. Hutnik, Energy Market 3, 102-108 (2015) (in Polish)

2. A. Gużda, N. Szmolke, BUSES - Technol. Oper. Transp. Syst. 6, 188-192 (2017) (in Polish)

3. M Harasimczuk, Electr. Eng. Pozn. Univ. Technol. Acad. Journals 87, 109-118 (2016)

4. Z. Cabrane, M. Ouassaid, M. Maaroufi, Int. Renew. Sustain. Energy Conf. (IRSEC), 185-190 (2014)

5. T. R. Ayodele, A. S. O. Ogunjuyigbe, B. E. Olateju J. Renew. Sustain. Energy 10, 13503 (2018)

6. V. M. Miñambres-Marcos, M. Á. GuerreroMartínez, F. Barrero-González, M. I. MilanésMontero, Sensors 17(8), 1856 (2017)

7. M. Á. Guerrero-Martínez, E. Romero-Cadaval, V. Minambres-Marcos, M. I. Milanés-Montero, J. Microelectron. Electron. Components Mater. 44(1), 40-52 (2014)

8. K S. K.ollimalla, M. K. Mishra, N. L. Narasamma, 2014, IEEE Trans. Sustain. Energy 5 (4), 11371144 (2014)

9. M. Benaouadj, A. Aboubou, M. Y. Ayad, M. Becherif, Energy Procedia 50, 333-341(2014)

10. N. Benyahia, H. Denoun, M. Zaouia, S. Tamalouzt, M. Bouheraoua, N. Benamrouche, T. Rekioua, S. Haddad, Energy Procedia 42, 539-548 (2013)
11. M. E. E. Glavin, P. K. W Chan S. Armstrong, W. G. G. Hurley, 13th Int. Power Electron. Motion Control Conf. EPE-PEMC, 10288042 (2008)

12. P.-O. Logerais, O. Riou, M. A. Camara, J.-F. Durastanti, J. Sol. Energy, 659014, 9 pages (2013)

13. H. Fakham, D. Lu, B. Francois, IEEE Trans. Ind. Electron. 58(1) 85-94 (2011)

14. M.,Guerrero, E. Romero, F. Barrero, M. Milanés, E. González, Electr. Rev.85(10), 188-195 (2009)

15. A. Fahad, T. Soyata, T. Wang, G. Sharma, W. Heinzelman, K. Shen, Conference: SOC Conference (SOCC), 2012 IEEE International, 13229941 (2012)

16. M. Hassanalieragh, T. Soyata, A. Nadeau, G. Sharma, 27th IEEE International System on Chip Conference (SOCC), 14719240 (2014)

17. A. Pressman, K. Billings, T. Morey, Switching Power Supply Design, Mc Graw-HiII, (2009)

18. http://www.ti.com/lit/an/slyt309/slyt309.pdf

19. W. Matelski, L. Wolski, S. Abramik, IAPGOS 3, 64-69 (2016)

20. D. Strąk, D. Michalski, M. Piasecka, BUSES Technol. Oper. Transp. Syst. 12, 428-433 (2017) (in Polish)

21. D. Strąk, M. Miesikowska, M. Piasecka, BUSES Technol. Oper. Transp. Syst. 12, 434-437 (2017) (in Polish) 